\title{
Article \\ Dynamic Analysis Method for Fault Propagation Behaviour of Machining Centres
}

\author{
Liming Mu ${ }^{1,2} \oplus$, Yingzhi Zhang ${ }^{1,2, *} \mathbb{D}$, Jintong Liu ${ }^{1,2}$, Fenli Zhai ${ }^{1,2}$ and Jie Song ${ }^{1,2}$ \\ 1 Key Laboratory of Reliability of CNC Equipment, Ministry of Education, Changchun 130022, China; \\ moulm19@mails.jlu.edu.cn (L.M.); jintongliu1324@jlu.edu.cn (J.L.); difl19@mails.jlu.edu.cn (F.Z.); \\ jiesong19@mails.jlu.edu.cn (J.S.) \\ 2 School of Mechanical and Aerospace Engineering, Jilin University, Changchun 130022, China \\ * Correspondence: zhangyz@jlu.edu.cn
}

check for updates

Citation: Mu, L.; Zhang, Y.; Liu, J.; Zhai, F.; Song, J. Dynamic Analysis Method for Fault Propagation Behaviour of Machining Centres. Appl. Sci. 2021, 11, 6525. https:// doi.org/10.3390/app11146525

Academic Editors: José Machado,

Filomena Soares,

Dariusz Mazurkiewicz,

Dario Antonelli and

Katarzyna Antosz

Received: 12 May 2021

Accepted: 14 July 2021

Published: 15 July 2021

Publisher's Note: MDPI stays neutral with regard to jurisdictional claims in published maps and institutional affiliations.

Copyright: (c) 2021 by the authors. Licensee MDPI, Basel, Switzerland. This article is an open access article distributed under the terms and conditions of the Creative Commons Attribution (CC BY) license (https:// creativecommons.org/licenses/by/ $4.0 /)$.

\begin{abstract}
Fault propagation behaviour analysis is the basis of fault diagnosis and health maintenance. Traditional fault propagation studies are mostly based on a priori knowledge of a causality model combined with rule-based reasoning, disregarding the limitations of experience and the dynamic characteristics of the system that cause deviations in the identification of critical fault sources. Thus, this paper proposes a dynamic analysis method for fault propagation behaviour of machining centres that combines fault propagation mechanisms with model structure characteristics. This paper uses the design structure matrix (DSM) to establish the fault propagation hierarchy structure model. Considering the correlation of fault time, the fault probability function of a component is obtained and the fault influence degree of nodes are calculated. By introducing the Copula and Coupling degree functions, the fault influence degree of the edges between the same level and different levels are calculated, respectively. This paper constructs a fault propagation intensity model by integrating the edge betweenness and uses it as an index to analyze real-time fault propagation behaviour. Finally, a certain type of machining centre is taken as an example for specific application. This study can provide as a reference for the fault maintenance and reliability growth of a machining centre.
\end{abstract}

Keywords: machining centre; DSM; Copula function; fault propagation intensity; fault propagation behaviour

\section{Introduction}

CNC technology and CNC machine tools are enabling the development of technologies and basic equipment towards emerging high-technology and cutting-edge industries [1]. Numerical control technology is extensively used in many countries worldwide to improve the capacity and level of the equipment manufacturing industry, and to improve market adaptability and competitiveness [2]. Machining centres are widely used because of their strong flexible processing capabilities. They have a strong technical advantage in the manufacturing field and have become the main processing equipment for various manufacturing enterprises.

A machining centre is a complex system composed of multiple components. Given the influence of system structure, working environment, human factors, and maintenance level, the usage of a machining centre becomes more complex. The system fault is not only related to the independent fault of the component but also to the propagation faults [3]. If the fault cannot be eliminated in a timely manner, it will affect the progress of the entire production and even cause the contract to fail to be performed as scheduled, resulting in irreparable economic losses to a company [4]. Currently, many companies have low levels of fault diagnosis and maintenance in their machining centres, especially in the fault diagnosis of a machining centre [5]. The cost [6] and time [7] spent on locating a fault source of a machining centre cannot be ignored and when the cause of the fault is determined, the time for troubleshooting will be significantly shortened. Therefore, clarifying the real-time fault 
propagation behaviour of a machining centre is crucial for the prediction and elimination of faults.

The current fault diagnosis methods can be summarized into four categories [8,9]: knowledge-based fault diagnosis [10-12], model-based fault diagnosis [13-15], signalbased fault diagnosis [16-18], and hybrid method-based fault diagnosis (a method that combines two or more methods) [19-22]. Fault diagnosis for machining centres mainly include diagnosis methods based on fault information monitoring, training models, and fault trees.

The diagnosis method based on fault information monitoring is concerned with monitoring information characteristics of each system component of a machining centre by means of sensors [23]. Through the test analysis software and the corresponding model, the fault information feature extraction is realized and the fault location is determined [24]. However, because the sensor is highly susceptible to the influence of the surrounding environment, the collected signal is not accurate enough and leads to a certain deviation of the diagnosis results. This method cannot detect all the usage information of a system; hence, it is mostly used for the fault diagnosis of system components and cannot realize the fault diagnosis of an entire system.

The diagnosis method based on training model is concerned with training models such as support vector machines [25-27] and neural networks [28-30] on the basis of constructing a machine fault information database. Then, on the basis of the input information that represents the fault symptom, the output information that reflects the fault cause is directly derived to realize the judgment of the machine fault; However, this method cannot accurately determine the fault location of a machine. Concurrently, when the machine is very expensive, establishing test samples is difficult, hence collecting numerous samples to train a model is impossible.

The diagnosis method based on fault trees is concerned with listing all the possible causes of machine faults successively from top to bottom [31]. By establishing the fault tree of a machining centre, faults can be checked individually [32]. However, this method uses the dependency of each fault mode to construct the fault tree and realizes the fault diagnosis on the basis of the simple logic gate and the average fault rate of the bottom event. Due to the neglecting of the correlation of fault mode, a deviation in the calculation of fault rate occurs and the structural characteristics of fault trees are not considered, thus resulting in a wrong diagnosis.

Given the shortcomings of the above diagnosis methods, some scholars use a petri net, cellular automaton, and complex networks with topological characteristics such as regular networks, scale-free networks, small-world networks, and random networks to establish fault propagation models to study fault propagation [33-36]. However, given the dependence of a model on the structure and the correlation of faults, a deviation occurs in the fault mechanism analysis and fault source location of a machining centre. In addition, the fault influence degree of system components obtained by traditional methods is mostly constant; in contrast, the fault influence degree of each system component will change over time. Thus, achieving the ideal effect in the fault diagnosis strategy is difficult.

Therefore, this paper proposes a fault propagation intensity evaluation method that is used to dynamically describe the fault propagation process of machining centre system components. Compared with the existing methods, the DSM-based fault propagation hierarchy structure model of machining centres established in this paper can more clearly demonstrate the relationship between system components. The fault influence degree of system components obtained in this paper are also time-varying, thereby more in line with engineering practice. Moreover, for the calculation of the influence degree of the edge between components, most of the previous studies used the same method to calculate the fault influence degree of each level and did not consider the difference of fault influence between different levels that will inevitably lead to the deviation in the fault propagation analysis results. This paper considers the difference of fault influence degree between different levels and uses the Copula function and coupling function to 
calculate the fault influence degree of the edges between the same level and different levels, respectively. The structural characteristics of the model and fault mechanism of the system is considered synthetically, thus the description is more reasonable. We use the value of the fault propagation intensity as an index to study the fault propagation behaviour of a machining centre, to identify the critical fault propagation path of a machining centre, and to provide a theoretical basis and practical reference for later fault detection and maintenance.

The remainder of this paper is organized as follows. Section 2 describes the method for evaluating the fault propagation intensity of machining centres on the basis of a fault propagation model. Section 3 introduces the dynamic analysis method of fault propagation behaviour of machining centres on the basis of the fault propagation intensity. Section 4 provides a case application of a machining centre to demonstrate the effectiveness of the proposed method. Section 5 engages in a discussion. Lastly, Section 6 presents our conclusions.

\section{Method for Evaluating Fault Propagation Intensity of Machining Centres on the Basis of the Fault Propagation Model}

Based on the basic working process and principle of machining centres, a machining centre is divided into modules and the relevant faults are identified in combination with the field fault data. Considering the fault correlation of components, a hierarchy structure model of machining centres' fault propagation on the basis of DSM is established. The Johnson method is applied to correct the component fault order and construct a timedependent component fault probability model. On this basis, the importance of component nodes is calculated to reflect the fault influence degree of component nodes. Considering the differences of fault influence degree of the edges at different levels, this paper uses the Copula function to calculate the influence degree of the edges at the same level and uses the coupling degree function to calculate the influence degree of the edges between different levels. Then, the component fault probability model is integrated to calculate the node's probability of fault propagation. Given that the topology of the model will also affect the propagation of the fault, the fault propagation intensity of machining centres can be evaluated by fusing the probability of the fault propagation with the edge betweenness of the structural model. The evaluation process of fault propagation intensity in machining centres is shown in Figure 1.

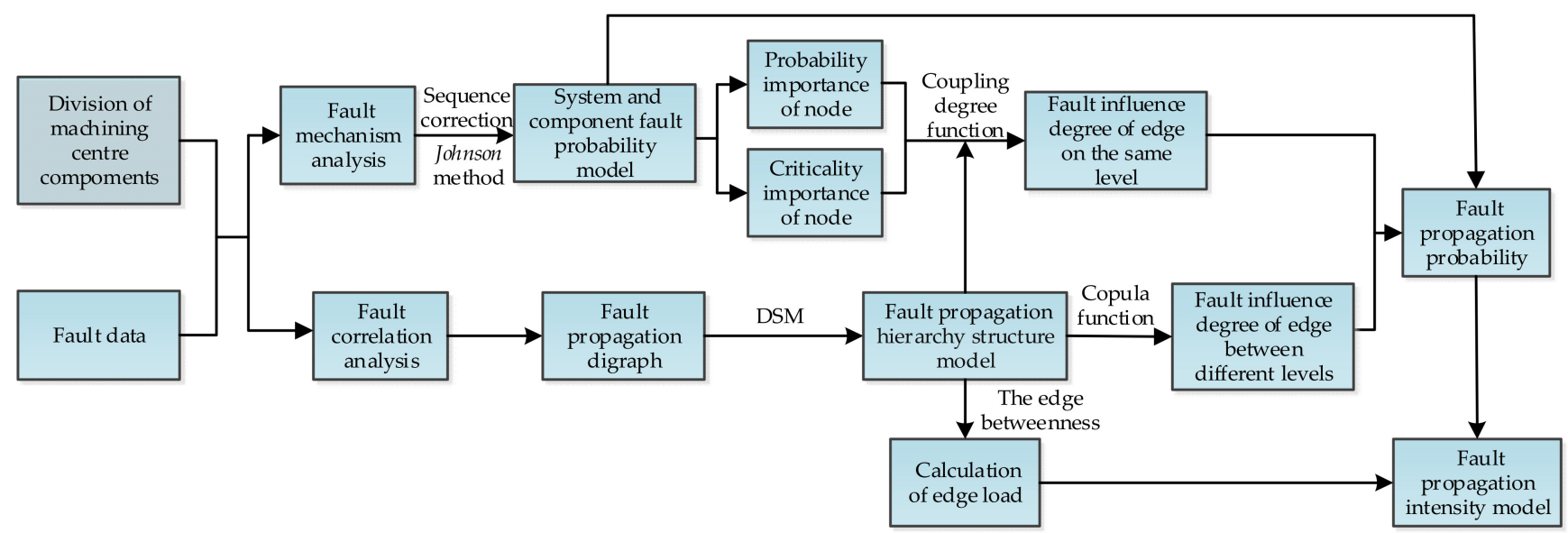

Figure 1. Evaluation process of the fault propagation intensity in machining centres. 


\subsection{Construction of the Hierarchy Structure Model of Fault Propagation in Machining Centres} Based on DSM

\subsubsection{General System Hierarchy Structure Modelling Process}

The system structure model describes the relationship structure between the components of the system with the concept of set. The model is a diagram that reflects the relationship between the components of the system. For machining centres, however, the relationship diagram is difficult to utilize for clearly reflecting the relationships between the components of the system. Through matrix and hierarchy processing, the related digraph of each system component is transformed into a hierarchy structure model that can clearly understand the structure of the system and relationship between the components of the system. Its general modelling process is shown in Figure 2.

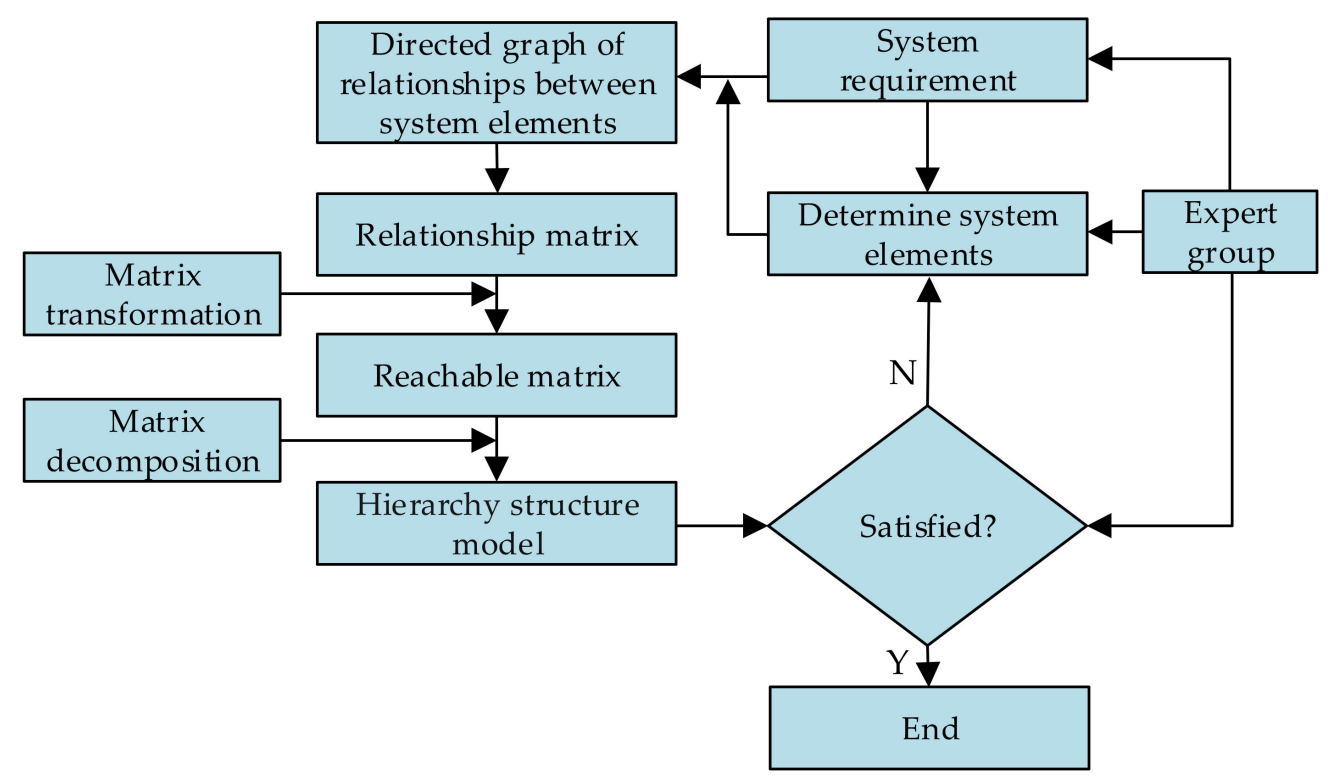

Figure 2. Schemes follow the same formatting.

2.1.2. Construction of the Hierarchy Structure Model of Fault Propagation in Machining Centres on the Basis of DSM

In accordance with the general modelling process of the hierarchy structure model, the machining centre is first divided into $n$ system components on the basis of the working process and principles of the machining centre, and the fault correlation analysis of the collected fault data is conducted and aided by the relevant experience of the system structure function and the fault diagnosis manual. Furthermore, the fault time of each system component in the machining centre and the fault propagation relationship among the components is determined. The system component is expressed as a node set: $V=\left\{v_{1}, v_{2}, \cdots, v_{n}\right\}$. The fault propagation relationship and connection relationship between system component nodes are represented by directed edge set $E=\left\{\left\langle v_{1}, v_{2}\right\rangle,\left\langle v_{2}, v_{3}\right\rangle, \cdots,\left\langle v_{m}, v_{n}\right\rangle\right\}$. Thus, a digraph $(G=(V, E))$ of fault propagation of a machining centre can be obtained. Then, according to the fault propagation digraph, the direct fault influence between the system components is expressed with a relation matrix $(A)$ and the reachable matrix is obtained according to the relation matrix. In addition, the reachable matrix is decomposed to realize the construction of the fault propagation hierarchy structure model.

To establish a clearer fault propagation hierarchy structure model, the design structure matrix (DSM) method is introduced [37]. In the form of binary values, ' 0 ' and ' 1 ' or ' $x$ ' and a blank space represent the relationship between the row and column elements in the 
design structure matrix $(\boldsymbol{M})$. The design structure matrix can be regarded as a reachable matrix. The elements in the design structure matrix are defined as follows:

$$
m_{i j}=\left\{\begin{array}{c}
1, v_{i} \text { has at least one dependency on } v_{j} \\
0, v_{i} \text { has nothing to do with } v_{j}
\end{array} \quad(i=1,2, \cdots, n ; j=1,2, \cdots, n)\right.
$$

The fault influence relationship between the system components of a machining centre can also be expressed as the dependency relationship between the elements in the design structure matrix. At this time, the elements are defined as follows:

$$
m_{i j}=\left\{\begin{array}{c}
1, v_{i} \text { has at least one effect on } v_{j} \\
0, v_{i} \text { has no effect on } v_{j}
\end{array} \quad(i=1,2, \cdots, n ; j=1,2, \cdots, n)\right.
$$

The modelling principle of the hierarchy structure model is based on the design structure matrix $(\boldsymbol{M})$ and according to the knowledge of matrix, row-column transformation is conducted. In addition, the design structure matrix is converted into the lower triangular matrix as much as possible to reduce the existence of positive and negative transfer relations in the matrix. To eliminate feedback information between modules, the risk of iteration is reduced [38]. The construction process of the fault propagation hierarchy structure model based on DSM is shown in Figure 3.

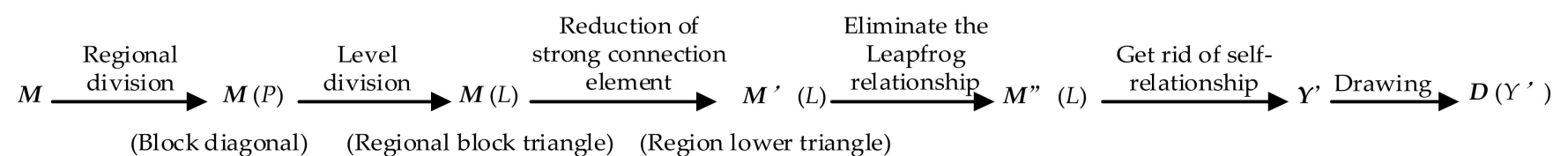

Figure 3. Flow chart of the hierarchy structure model construction based on DSM.

Based on the hierarchy sequence obtained by the DSM-based hierarchy model construction process, the appearance layer is classified as the fault absorption layer in the fault propagation model, the root layer is classified as the fault initiation layer, and the remaining layers are classified as the fault propagation layers. The number of fault propagation layers may vary according to the needs of the research object. Based on this, the hierarchy structure model of fault propagation of system components is drawn.

\subsection{Calculation of Fault Propagation Probability of Machining Centre System Components}

2.2.1. Calculation of Machining Centre System Components' Fault Probability

All $n$ data of machining centres' fault data and right truncation data are sorted and recorded as $j(1 \leq j \leq n)$. Then, only $m$ fault data of a certain component of a machining centre are sorted from small to large and are recorded as $i(1 \leq i \leq m)$. The order number $n$ of the $i$-th fault data is as follows:

$$
r_{i}=r_{i-1}+\frac{n+1-r_{i-1}}{n+2-j}
$$

The corrected component fault time order number is substituted into the median rank equation to obtain the empirical distribution function of the component, as follows:

$$
r_{i}=\frac{r_{i}-0.3}{n+0.4}
$$

The Weibull distribution commonly used in engineering is taken as the hypothetical distribution of the fault interval time of machining centre components. In this paper, 
Weibull distribution is used to construct the reliability model and the cumulative fault distribution function is as follows:

$$
F(t)=1-\exp \left[-\left(\frac{t}{\beta}\right)^{\gamma}\right], t \geq 0,
$$

where $\beta$ represents scale parameter, $\beta>0, \gamma$ represents shape parameter, and $\gamma>0, t$ is a time variable, $t \geq 0$.

Equation (5) is transformed as follows:

$$
\ln [\ln (1 /(1-F(t)))]=\gamma \ln t+\gamma \ln \beta
$$

The linear regression model is fitted between $\ln [\ln (1 /(1-F(t)))]$ on the left side of the equation and $\ln t$ on the right side. The Weibull model parameter value $\hat{\beta}$ and $\hat{\gamma}$ can be obtained on the basis of the fault information and empirical distribution function value. The model test value $(\rho)$ is calculated by the linear correlation coefficient test method. Next, the minimum value $\left(\rho_{\alpha}\right)$ of the correlation coefficient is calculated on the basis of the number of fault data $(n)$ and significance level $(\alpha)$. When $\rho>\rho_{\alpha}$, it is considered that $\ln [\ln (1 /(1-F(t)))]$ and $\ln t$ are linearly related and the fault data is subject to the assumed distribution. Otherwise, the hypothesis is rejected.

2.2.2. Determination of the Influence Degree between Components of Machining Centres

Importance refers to the contribution to the fault probability of the whole machine when a system component fails; it is a time-dependent function and can characterize both the structure of the system and a parameter of the reliability of the system components [39]. The importance of system components is quantitatively described and called the importance of system components. In this paper, it is regarded as the influence degree of a system component to reflect the influence degree of a whole machine fault caused by the fault of a certain system component.

(1) Calculation of Probability Importance of System Component Nodes

In the late 1960s, Birnbaum put forward the Birnbaum probability importance for practical production [40]. The idea of probability importance is introduced by considering the contribution of reducing the fault probability of system components to reducing the fault probability of the whole system.

When any system component of a machining centre fails, it may cause the whole machine to fail. Hence, the relationship between the system components of a machining centre can be regarded as the series relationship. According to this structural relationship, the fault probability function of the system components can be used to describe the fault probability function of a whole machining centre. The fault probability function is a function of time and their relationships are expressed in Equation (7):

$$
F_{Z}(t)=1-\left[\left(1-F_{1}(t)\right)\left(1-F_{2}(t)\right) \cdots\left(1-F_{i}(t)\right)\right] .
$$

In addition, the equation for calculating the probability importance of system component nodes are shown in Equation (8):

$$
I_{P}\left(v_{i}\right)=\frac{\partial F_{Z}(t)}{\partial F_{i}(t)} i=1,2, \cdots, n,
$$

where $I_{P}\left(v_{i}\right)$ is the probability importance of the system component node, $F_{Z}(t)$ is the fault probability function of the whole machine, and $F_{i}(t)$ is the fault probability function of the system component node. For any two-system component nodes, regarding $v_{i}$ and $v_{j}$, if $I_{P}\left(v_{i}\right)>I_{P}\left(v_{j}\right)$ exists at some time then $v_{i}$ is more important than $v_{j}$. 


\section{(2) Calculation of the Criticality Importance of Nodes}

The probability importance expresses that the fault probability of the system component node changes by one unit, resulting in the change of the fault probability of the whole system. Given that the probability of the fault of each system component node is different, the difficulty of generating a unit change is also different. Therefore, the criticality importance is introduced to describe the properties that the probability importance cannot reflect. Criticality importance was first proposed by Lambert [41]. In the case of a given fault of a whole system, the conditional probability that the whole machine is in a certain state when the critical system component node $v_{i}$ fails at time $t$. The core idea is to improve the non-reliable system components rather than to further improve the reliable system components.

Therefore, the criticality importance $\left(I_{C}\left(v_{i}\right)\right)$ of the system component node is defined as:

$$
I_{C}\left(v_{i}\right)=\frac{F_{i}(t)}{F_{Z}(t)} \cdot \frac{\partial F_{Z}(t)}{\partial F_{i}(t)}=\frac{F_{i}(t)}{F_{Z}(t)} \cdot I_{P}\left(v_{i}\right) .
$$

For a machining centre, when the system component node $v_{i}$ fails and the fault is passed to the component node $v_{j}$ at a certain value, $v_{j}$ is affected by the fault and the component node $v_{i}$ is also affected by the component node $v_{j}$. There also exists a certain influence value on the directed edge between the two component nodes. This value represents the influence ability of the component node $v_{i}$ fault to cause the fault of its connected component node $v_{j}$. However, the fault influence degree of the edge of the same level differs from that of the different layers, hence it should be considered separately.

2.2.3. Calculation of the Fault Influence Degree of Edges in the Same Level Based on the Copula Function

In this paper, it is assumed that a whole machine has $n$ fault-related system components and its reliability function is $R\left(t_{i}\right), i=1,2, \cdots, n$ and the joint reliability function of these system components is $R\left(t_{1}, t_{2}, \cdots, t_{n}\right)$. Based on the Copula theory and Sklar theorem [42-44], a Copula function can be uniquely determined. It is expressed as follows:

$$
C\left(R_{1}(x), R_{2}(x), \cdots, R_{n}(x)\right)=\exp \left\{-\left[\sum_{i=1}^{n}\left(-\ln R_{i}(t)\right)^{1 / \theta}\right]^{\theta}\right\},
$$

where $\theta$ is the parameter of the Copula function to characterize the degree of association between the system components $(\theta \in(0,1])$.

Given that the calculation process of the Copula function parameters is relatively complex, this paper introduces a relatively intelligent artificial fish swarm algorithm [45] and uses MATLAB software to solve the parameters of the Copula function.

The following relationship exists between the fault probability function and reliability function:

$$
F(t)=1-\exp \left[-\left(\frac{t}{\beta}\right)^{\gamma}\right]=1-R(t) .
$$

As expressed in Equation (10), the degree of correlation between components obtained from the perspective of the reliability function is represented by $\theta$ and as expressed in Equation (11), $F(t)=1-R(t)$. Therefore, the fault influence degree of the edge at the same level in a machining centre is $I\left(v_{i}, v_{j}\right)=1-\theta$ and the greater the value is, the greater the fault influence degree of the edge will be.

2.2.4. Calculation of the Fault Influence Degree of Edges at Different Levels Based on the Coupling Degree Function

In Reference [46], the effect function is used to describe the impact of a certain subsystem change on the whole machine, while the coupling degree model is used to characterize the coupling degree between subsystems. Thus, the importance of the node is taken as the 
effect function value and a model of the fault coupling degree is established to reflect the fault influence value between the components. The calculation equation is expressed in Equation (12):

$$
I\left(v_{i}, v_{j}\right)=2\left[\frac{I_{C}\left(v_{i}\right) I_{C}\left(v_{j}\right)}{\left(I_{C}\left(v_{i}\right)+I_{C}\left(v_{j}\right)\right)^{2}}\right]^{1 / 2},
$$

where $I\left(v_{i}, v_{j}\right) \in(0,1)$ and is the fault influence degree between $v_{i}$ and $v_{j}$. This value is used to characterize the effect of this edge on fault propagation. $I_{C}\left(v_{i}\right)$ and $I_{C}\left(v_{j}\right)$ are the critical importance values of $v_{i}$ and $v_{j}$, respectively.

\subsubsection{Construction of the Fault Propagation Probability Model for Machining Centre} System Components

Based on the hierarchy model of a machining centre and the fault propagation mechanism, the state of a system component node depends on its own fault probability, which the influence of upstream component node is dependant on. The fault influence between the nodes reflects the possibility of a fault of the component node to cause another component fault to be associated with it. Therefore, by integrating the fault probability $\left(F_{i}(t)\right)$ of the node and the fault influence degree $\left(I\left(v_{i}, v_{j}\right)\right)$ between the system component nodes, the value of the fault propagation probability between system components can be obtained. The equation is as follows:

$$
P\left(v_{i}, v_{j}\right)(t)=F_{i}(t) I\left(v_{i}, v_{j}\right)
$$

\subsection{Evaluation of Fault Propagation Intensity of a Machining Centre Based on the Fault Propagation Model}

Given that the influence of the structural characteristics of the hierarchy model of fault propagation cannot be disregarded, the edge betweenness that represents the structural characteristics of the model is considered [47]. The larger the value is, the stronger its influence on the whole model will be.

In this paper, the edge betweenness is defined as the proportion of the number of times that all paths pass through the edge $E\left\langle v_{i}, v_{j}\right\rangle$ in the graph model. The edge betweenness of the directed edge $E\left\langle v_{i}, v_{j}\right\rangle$ connecting $v_{i}$ and $v_{j}$ is denoted by $L\left(v_{i}, v_{j}\right)$ that can be calculated by the following equation:

$$
L\left(v_{i}, v_{j}\right)=\sum_{\substack{v_{i}, v_{j}, v_{e}, v_{f} \\(e, f) \neq(i, j)}} \frac{\kappa_{e f} E\left\langle v_{i}, v_{j}\right\rangle}{\kappa_{e f}}
$$

where $\boldsymbol{\kappa}_{e f}$ is number of paths between any of the nodes, and $v_{e}, v_{f}$, and $\boldsymbol{\kappa}_{e f} E\left\langle v_{i}, v_{j}\right\rangle$ are the number of paths between $v_{e}$ and $v_{f}$ passing through edge $E\left\langle v_{i}, v_{j}\right\rangle$.

In this paper, the fault propagation intensity model of a machining centre is established from two angles of the fault propagation probability and the edge betweenness of the hierarchy model. This value of the fault propagation intensity is used as an index to measure the severity of the impact of the fault on the whole machine through the path. The calculation equation for defining the fault propagation intensity $\operatorname{In}\left(v_{i}, v_{j}\right)$ of a machining centre is as follows:

$$
\operatorname{In}\left(v_{i}, v_{j}\right)=\frac{1}{2}\left(\frac{P\left(v_{i}, v_{j}\right)}{\sum P\left(v_{i}, v_{j}\right)}+\frac{L\left(v_{i}, v_{j}\right)}{\sum L\left(v_{i}, v_{j}\right)}\right),
$$

where $\sum P\left(v_{i}, v_{j}\right)$ is the sum of the fault propagation probabilities of each directed edge. $\sum L\left(v_{i}, v_{j}\right)$ is the sum of the edge betweenness of each directed edge. 


\section{Dynamic Analysis of the Fault Propagation Behaviour of a Machining Centre Based on the Fault Propagation Intensity}

To analyze the real-time fault propagation behaviour of a machining centre, the propagation range of the fault should be clarified to determine whether the propagation of the fault can be achieved. As expressed by the system and product safety manual [48], the occurrence of the fault propagation is within a certain interval and when the probability of fault propagation is greater than the threshold of $10^{-8}$, the case of fault propagation may occur.

Therefore, the probability of $v_{i}$ fault to propagate to $v_{j}$ can be obtained as follows:

$$
P_{E}\left(v_{i}, v_{j}\right)=\sum_{b=1}^{w} P_{b}\left(v_{i}, v_{j}\right),\left(P_{b}\left(v_{i}, v_{j}\right)=\prod P\left(v_{i}, v_{j}\right)\right),
$$

where $b$ is one of the several paths in which a fault propagates from node $v_{i}$ to $v_{j} . P_{b}\left(v_{i}, v_{j}\right)$ is the fault propagation probability of the path. $w$ is the number of paths from node $v_{i}$ to $v_{j}$.

On the basis of Equation (16), it can be clarified whether the fault can propagate in the fault propagation model and then realize the determination of critical nodes and the fault propagation path. The process of the determination of critical nodes at each level is shown in Figure 4.

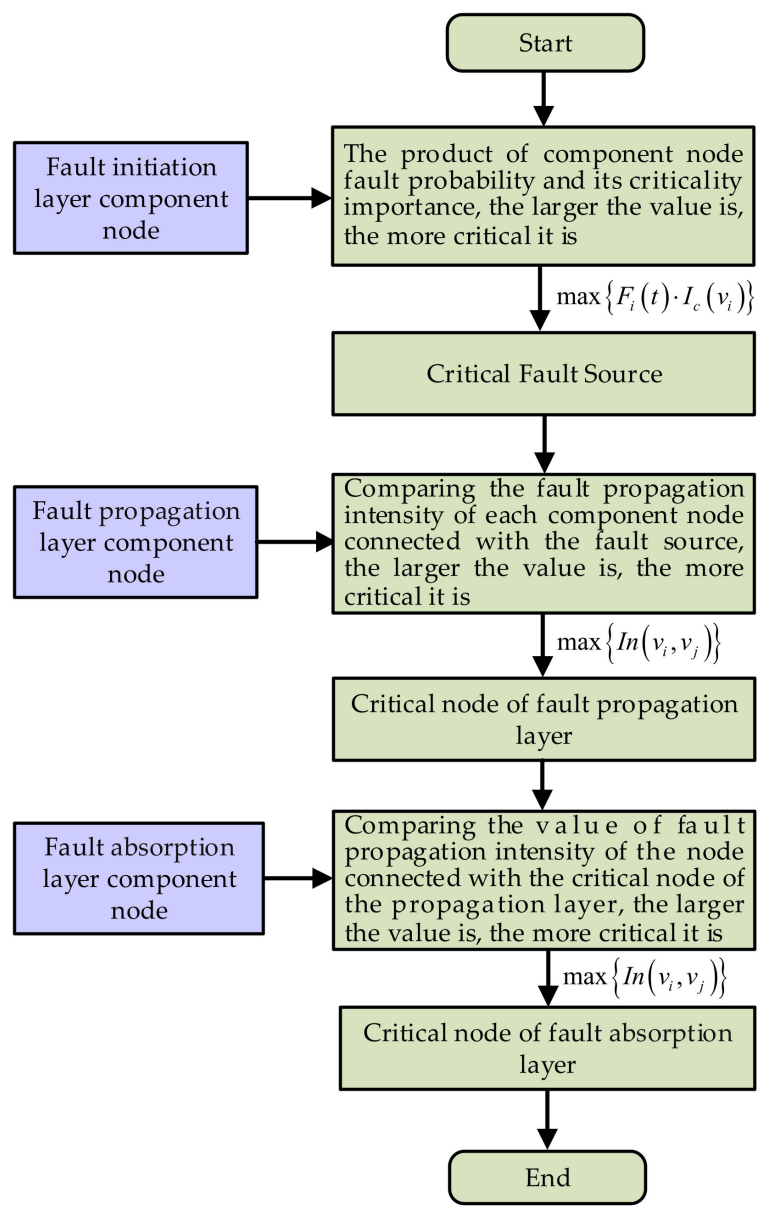

Figure 4. Flow chart expressing how to determine critical nodes at each level.

As illustrated in Figure 4, to determine the system components of the fault initiation layer, the product of component fault probability and its own criticality importance at time $t$ is calculated; in turn, the larger the value, the more critical it is. The critical component of the fault initiation layer is considered as the fault source. To determine the system components of the fault propagation layer, according to the hierarchy model of the fault 
propagation intensity of a machining centre, the system components in the propagation layer connected with the fault source are determined at time $t$ and the fault propagation intensity values of the system components connected with the fault source are calculated; in turn, the larger the value, the more critical it is. Similarly, the fault propagation intensity values of each system component connected with the critical nodes of the fault propagation layer in the fault absorption layer are calculated; in turn, the larger the value, the more critical it is and the critical nodes of the fault absorption layer are determined.

The path composed of critical nodes is the critical fault propagation path, according to which fault prevention and maintenance can be conducted.

\section{Case Application of a Machining Centre}

The fault propagation behaviour analysis method proposed in this paper has a certain general applicability and can provide guidance for the analysis of fault propagation behaviour of other complex systems. This paper selects the machining centre commonly used by various manufacturing companies as an example to illustrate the specific application.

\subsection{Implementation}

In this section, we take MDH series horizontal machining centres as the research object that are mainly used for processing rotary parts. We collected 108 on-site fault information details of 36 machining centres of this series during the course of one year. After fault analysis, we can determine whether each component fault is an independent fault or a related fault. If it is a related fault, the antecedent component that caused the component fault will be determined through fault analysis. For example, when the workpiece cannot be clamped, the tool magazine system (T) is the direct fault location but the root cause is that the workpiece cannot be clamped due to insufficient pressure in the hydraulic system $(\mathrm{H})$. At this time, the faulty component is the tool magazine system $(\mathrm{T})$ and its antecedent component is the hydraulic system $(\mathrm{H})$. Considering the existence of this propagation fault, there is likely to be a directed arrow pointing from the hydraulic system $(\mathrm{H})$ to the tool magazine system (T). Similarly, when the servo motor fails, the fault location is the feed system (F) but the root cause is the abnormality of the spindle system (B). Therefore, there is likely to be a directed arrow from the spindle system (B) to the feed system (F). In this manner, we can identify other related faults. The statistical analysis results of the related faults are shown in Table 1.

Table 1. Statistical analysis of the related faults in machining centre system components.

\begin{tabular}{ccc}
\hline Fault Component & Antecedent Component & Frequency \\
\hline T & B & 3 \\
F & B & 2 \\
B & NC & 1 \\
F & NC & 1 \\
T & H & 1 \\
B & H & 1 \\
B & D & 1 \\
NC & D & 1 \\
W & D & 1 \\
F & R & 1 \\
T & R & 1 \\
B & R & 1 \\
F & W & 1 \\
F & K & 1 \\
B & Q & 2 \\
T & Q & 1 \\
\hline
\end{tabular}

As expressed in Table 1, combined with the knowledge of graph theory, the fault propagation relationship of a machining centre is modelled. We do not consider compo- 
nents with uncorrelated faults such as the workbench $(U)$. Thus, we can obtain the fault propagation digraph of a machining centre as shown in Figure 5.

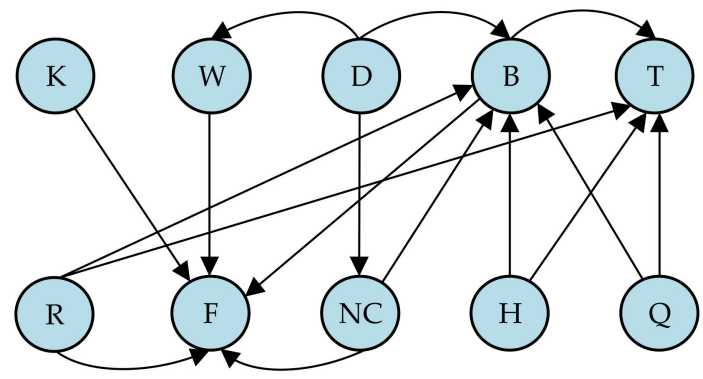

$$
\begin{array}{ll}
\text { K-Chip removal system } & \text { R-Lubrication system } \\
\text { W-Cooling system } & \text { F-Feed system } \\
\text { D- Electrical system } & \text { NC-Numerical control system } \\
\text { B-Spindle system } & \text { H-Hydraulic system } \\
\text { T-Tool magazine } & \text { Q-Pneumatic system }
\end{array}
$$

Figure 5. Fault propagation digraph of a machining centre.

As expressed in the fault propagation digraph of a machining centre in Figure 5, the relationship matrix $(\boldsymbol{A})$ and the design structure matrix $(\boldsymbol{M})$ can be obtained as follows:

$$
\begin{gathered}
\mathrm{B} \\
\mathrm{A}=\mathrm{T} \\
\mathrm{T} \\
\mathrm{F} \\
\mathrm{NC} \\
\mathrm{H} \\
\mathrm{D} \\
\mathrm{Q} \\
\mathrm{R} \\
\mathrm{W} \\
\mathrm{K} \\
\mathrm{K}
\end{gathered}\left[\begin{array}{cccccccccc}
0 & 1 & 1 & 0 & 0 & 0 & 0 & 0 & 0 & 0 \\
0 & 0 & 0 & 0 & 0 & 0 & 0 & 0 & 0 & 0 \\
0 & 0 & 0 & 0 & 0 & 0 & 0 & 0 & 0 & 0 \\
1 & 0 & 1 & 0 & 0 & 0 & 0 & 0 & 0 & 0 \\
1 & 1 & 0 & 0 & 0 & 0 & 0 & 0 & 0 & 0 \\
1 & 1 & 0 & 0 & 0 & 0 & 0 & 0 & 0 & 0 \\
1 & 1 & 1 & 0 & 0 & 0 & 0 & 0 & 0 & 0 \\
0 & 0 & 1 & 0 & 0 & 0 & 0 & 0 & 0 & 0 \\
0 & 0 & 1 & 0 & 0 & 0 & 0 & 0 & 0 & 0
\end{array}\right]
$$

The element 1 in the matrix $\boldsymbol{M}$ indicates that the fault of the system component $i$ impacts $j$. Contrarily, 0 indicates that no impact exists.

Thus, on the basis of the modelling process of the DSM fault propagation hierarchy structure model, the fault propagation DSM model of a machining centre can be obtained as shown in Figure 6. The diagonal elements in Figure 6 are represented by black squares. 


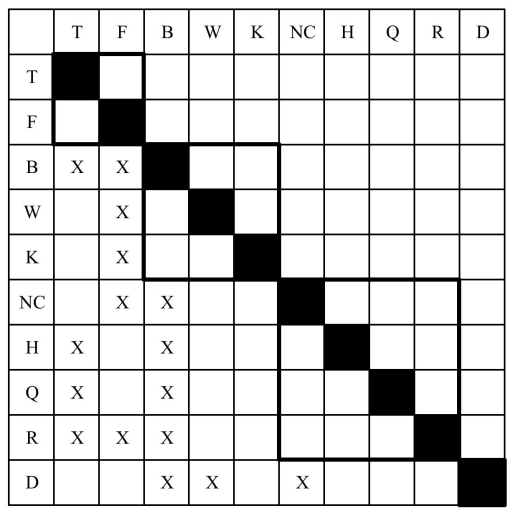

Figure 6. The fault propagation DSM model of a machining centre.

On the basis of Figure 6, we can derive the result of module division after the DSM modeling processing: the first-layer system components are ( $\mathrm{T}, \mathrm{F})$, the second-layer system components are (B, W, K), the third-layer system components are $(\mathrm{NC}, \mathrm{H}, \mathrm{Q}, \mathrm{R})$, and the fourth-layer system component is (D). The system components of the first layer, which is the appearance layer, are classified as the fault absorption layer in the fault propagation model. The system components of the fourth layer, the root layer, are classified as the fault initiation layer and the remaining layers are classified as the fault propagation layers. Thus, the fault propagation hierarchy structure model of a machining centre can be obtained as shown in Figure 7.

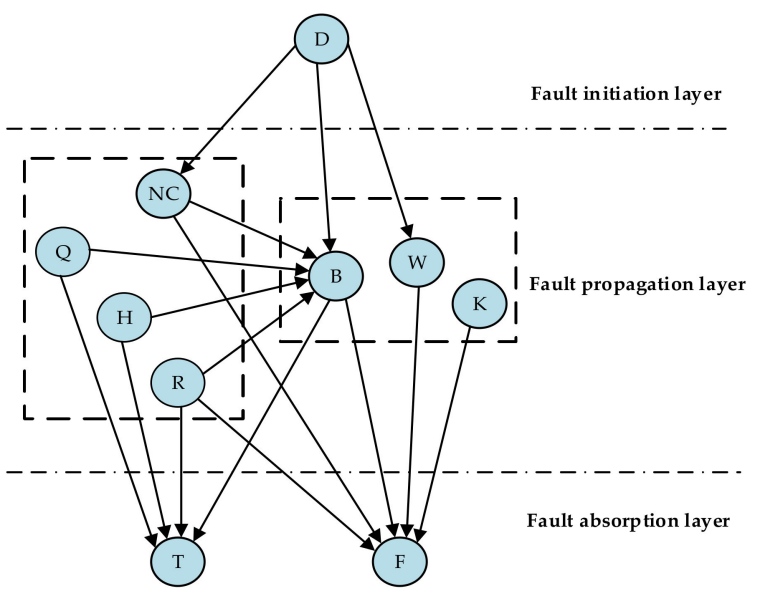

Figure 7. Hierarchy structure model of fault propagation in a machining centre.

On the basis of obtaining the fault information of a machining centre, we calculated the fault probability function of each component according to the calculation method presented in Section 2.2.1. Considering the impact of the timing truncation test and the fault time truncation on the sequence of the fault data, we use the Johnson method to modify it. The parameters of the fault probability model are then estimated and the distribution hypothesis test is passed. Finally, the fault probability function of each component can be obtained as shown in Table 2 and the function curve is illustrated in Figure 8.

Similarly, the fault probability function of a whole machining centre is $F_{Z}(t)=1-$ $\exp \left[-(t / 620.984)^{0.951}\right]$.

According to Table 2 and Equations (9) and (10), the probability importance and criticality importance of each system component node can be obtained at any time. The function curves of probability importance and criticality importance of each system component node are illustrated in Figures 9 and 10, respectively. 
Table 2. Fault probability function of system components in a machining centre.

\begin{tabular}{cc}
\hline Component Code & Fault Probability Function \\
\hline T & $F_{T}(t)=1-\exp \left[-(t / 2791.105)^{1.015}\right]$ \\
B & $F_{B}(t)=1-\exp \left[-(t / 7832.664)^{0.641}\right]$ \\
R & $F_{R}(t)=1-\exp \left[-(t / 8161.512)^{0.791}\right]$ \\
H & $F_{\mathrm{H}}(\mathrm{t})=1-\exp \left[-(\mathrm{t} / 8905.062)^{0.656}\right]$ \\
NC & $\mathrm{F}_{\mathrm{NC}}(\mathrm{t})=1-\exp \left[-(\mathrm{t} / 7912.399)^{0.542}\right]$ \\
$\mathrm{D}$ & $\mathrm{F}_{\mathrm{D}}(\mathrm{t})=1-\exp \left[-(\mathrm{t} / 7935.696)^{0.771}\right]$ \\
$\mathrm{Q}$ & $\mathrm{F}_{\mathrm{Q}}(\mathrm{t})=1-\exp \left[-(\mathrm{t} / 27503.400)^{0.524}\right]$ \\
$\mathrm{F}$ & $\mathrm{F}_{\mathrm{F}}(\mathrm{t})=1-\exp \left[-(\mathrm{t} / 2606.440)^{1.295}\right]$ \\
$\mathrm{W}$ & $\mathrm{F}_{\mathrm{W}}(\mathrm{t})=1-\exp \left[-(\mathrm{t} / 4145.720)^{0.910}\right]$ \\
$\mathrm{K}$ & $\mathrm{F}_{\mathrm{K}}(\mathrm{t})=1-\exp \left[-(\mathrm{t} / 5960.776)^{0.931}\right]$ \\
$\mathrm{U}$ & $\mathrm{F}_{\mathrm{U}}(\mathrm{t})=1-\exp \left[-(\mathrm{t} / 6869.766)^{0.773}\right]$ \\
\hline
\end{tabular}

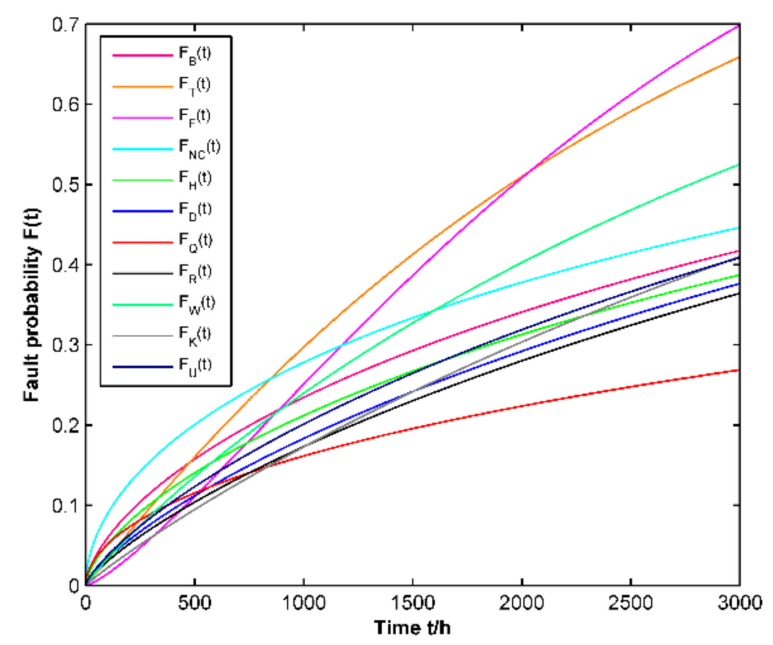

Figure 8. Fault probability function curve of machining centre system components.

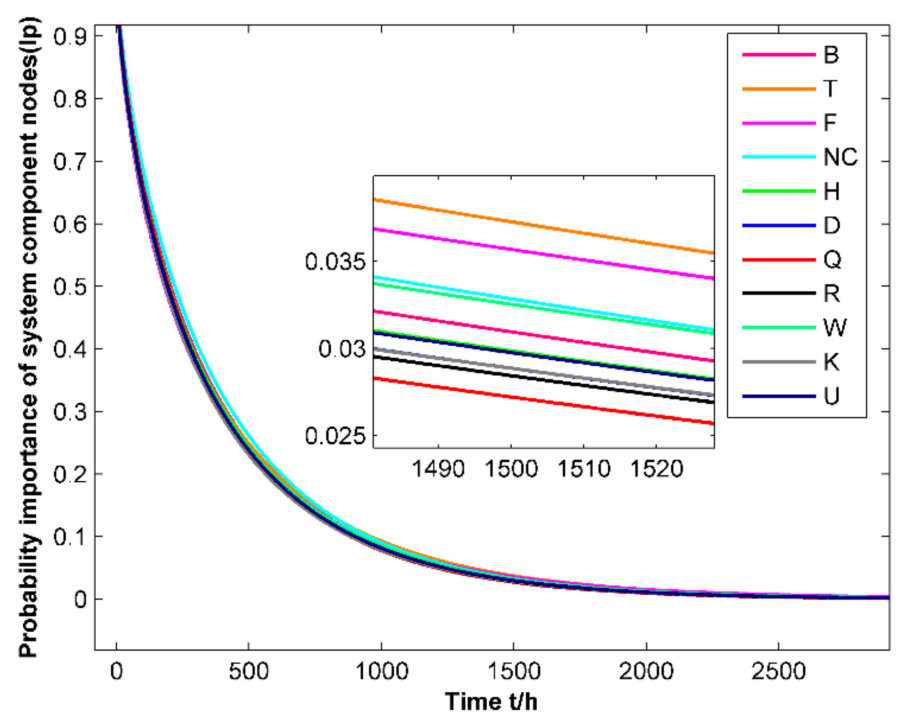

Figure 9. Probability importance function curve of system component nodes. 


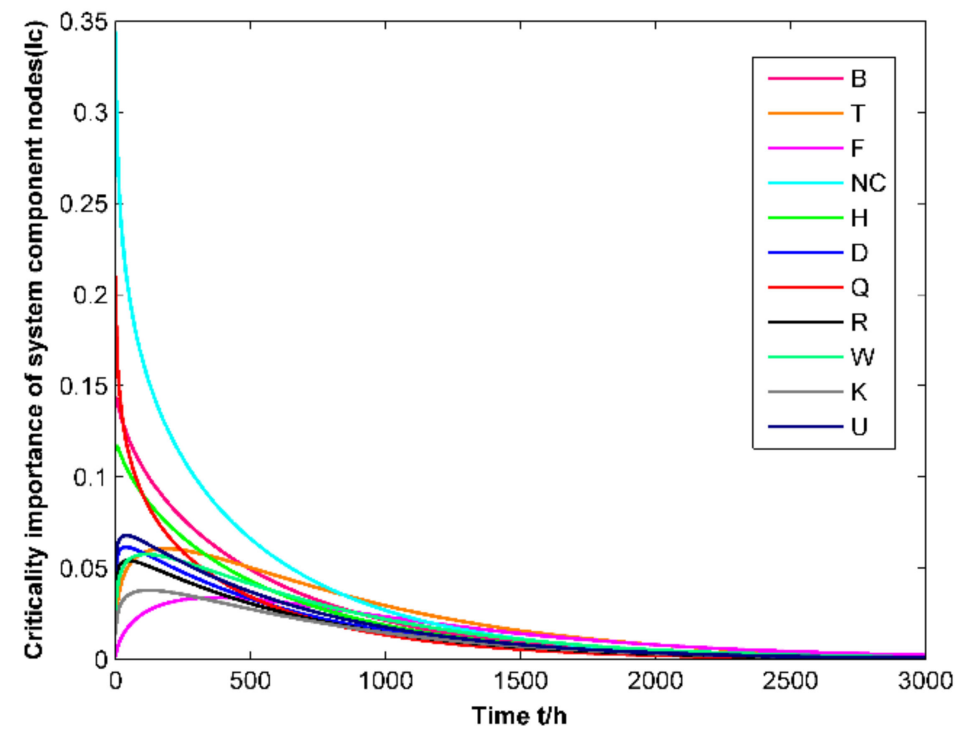

Figure 10. Criticality importance function curve of system component nodes.

Given that the values of probability and the criticality importance of system components are varied, this paper takes $t=1500 \mathrm{~h}$ as an example to illustrate this concept. By substituting the fault probability values of system components obtained from Table 2 into Equations (9) and (10), the probability importance and criticality importance of each system component node at $\mathrm{t}=1500 \mathrm{~h}$ can be obtained as shown in Table 3 .

Table 3. Probability importance and criticality importance of each system component at $1500 \mathrm{~h}$.

\begin{tabular}{ccc}
\hline Component Code & $\boldsymbol{I}_{\boldsymbol{P}}\left(\boldsymbol{v}_{\boldsymbol{i}}\right)$ & $\boldsymbol{I}_{\boldsymbol{C}}\left(\boldsymbol{v}_{\boldsymbol{i}}\right)$ \\
\hline $\mathrm{B}$ & 0.1399 & 0.0455 \\
$\mathrm{~T}$ & 0.1669 & 0.0754 \\
$\mathrm{~K}$ & 0.1613 & 0.0692 \\
$\mathrm{NC}$ & 0.1485 & 0.0550 \\
$\mathrm{H}$ & 0.1350 & 0.0400 \\
$\mathrm{D}$ & 0.1305 & 0.0350 \\
$\mathrm{Q}$ & 0.1230 & 0.0267 \\
$\mathrm{R}$ & 0.1285 & 0.0329 \\
$\mathrm{~W}$ & 0.1471 & 0.0534 \\
$\mathrm{~K}$ & 0.1305 & 0.0350 \\
\hline
\end{tabular}

On the basis of Equations (10) and (11), combined with Figure 7, the edge fault influence value of the same level at $1500 \mathrm{~h}$ can be calculated as shown in Table 4.

Table 4. Fault influence degree of the edge at the same level at $1500 \mathrm{~h}$.

\begin{tabular}{cc}
\hline Directed Edge & $\boldsymbol{I}\left(\boldsymbol{v}_{i}, \boldsymbol{v}_{j}\right)$ \\
\hline$E\left(v_{R}, v_{B}\right)$ & 0.9870 \\
$E\left(v_{H}, v_{B}\right)$ & 0.9876 \\
$E\left(v_{Q}, v_{B}\right)$ & 0.9808 \\
$E\left(v_{N C}, v_{B}\right)$ & 0.9914 \\
\hline
\end{tabular}

In reference to Equation (12), Table 3, and Figure 7, the edge fault influence value between different levels in the fault propagation hierarchy structure model of a machining centre at $1500 \mathrm{~h}$ is calculated. The results are detailed in Table 5. 
Table 5. Fault influence degree of the edge between different levels at $1500 \mathrm{~h}$.

\begin{tabular}{cccc}
\hline Directed Edge & $\boldsymbol{I}\left(\boldsymbol{v}_{\boldsymbol{i}}, \boldsymbol{v}_{j}\right)$ & Directed Edge & $\boldsymbol{I}\left(\boldsymbol{v}_{\boldsymbol{i}}, \boldsymbol{v}_{j}\right)$ \\
\hline$E\left(v_{D}, v_{B}\right)$ & 0.9915 & $E\left(v_{B}, v_{T}\right)$ & 0.9660 \\
$E\left(v_{R}, v_{T}\right)$ & 0.9153 & $E\left(v_{B}, v_{F}\right)$ & 0.9783 \\
$E\left(v_{D}, v_{N C}\right)$ & 0.9751 & $E\left(v_{R}, v_{F}\right)$ & 0.9344 \\
$E\left(v_{D}, v_{W}\right)$ & 0.9781 & $E\left(v_{H}, v_{T}\right)$ & 0.9484 \\
$E\left(v_{W}, v_{F}\right)$ & 0.9917 & $E\left(v_{K}, v_{F}\right)$ & 0.9446 \\
$E\left(v_{N C}, v_{F}\right)$ & 0.9934 & $E\left(v_{Q}, v_{T}\right)$ & 0.8741 \\
\hline
\end{tabular}

On the basis of Tables 4 and 5 , the $1500 \mathrm{~h}$ fault propagation hierarchy model of a machining centre based on fault influence degree can be obtained as shown in Figure 11.

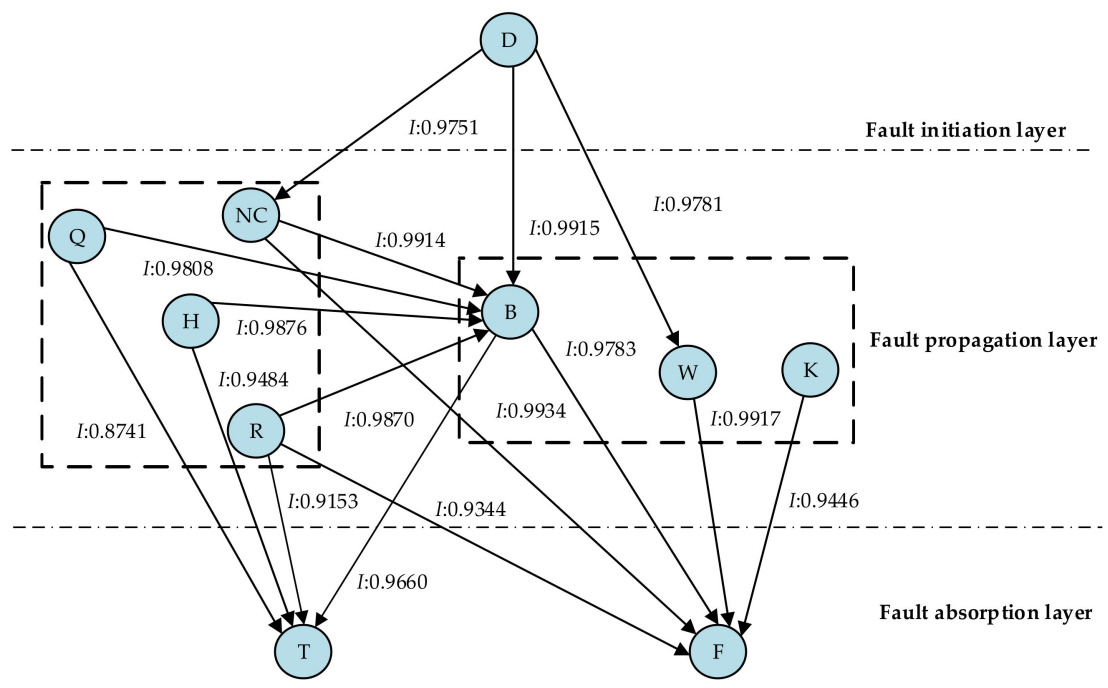

Figure 11. Hierarchy structure model of fault propagation of a machining centre based on the fault influence degree.

By substituting the data in Tables 2, 4 and 5 into Equation (13), the fault propagation probability of each system component at any time can be obtained. In addition, the calculation results of the $1500 \mathrm{~h}$ example are presented in Table 6.

Table 6. Fault propagation probability of the directed edge at $1500 \mathrm{~h}$.

\begin{tabular}{cccc}
\hline Directed Edge & $\boldsymbol{P}\left(\boldsymbol{v}_{i}, v_{j}\right)$ & Directed Edge & $\boldsymbol{P}\left(\boldsymbol{v}_{i}, v_{j}\right)$ \\
\hline$E\left(v_{R}, v_{B}\right)$ & 0.3308 & $E\left(v_{Q}, v_{B}\right)$ & 0.2397 \\
$E\left(v_{D}, v_{B}\right)$ & 0.3246 & $E\left(v_{B}, v_{T}\right)$ & 0.2639 \\
$E\left(v_{N C}, v_{B}\right)$ & 0.3315 & $E\left(v_{B}, v_{F}\right)$ & 0.2358 \\
$E\left(v_{H}, v_{B}\right)$ & 0.2830 & $E\left(v_{R}, v_{T}\right)$ & 0.2365 \\
$E\left(v_{D}, v_{N C}\right)$ & 0.2866 & $E\left(v_{R}, v_{F}\right)$ & 0.2534 \\
$E\left(v_{D}, v_{W}\right)$ & 0.2274 & $E\left(v_{H}, v_{T}\right)$ & 0.2284 \\
$E\left(v_{W}, v_{F}\right)$ & 0.2109 & $E\left(v_{K}, v_{F}\right)$ & 0.1919 \\
$E\left(v_{N C}, v_{F}\right)$ & 0.2153 & $E\left(v_{Q}, v_{T}\right)$ & 0.1711 \\
\hline
\end{tabular}

On the basis of the fault propagation hierarchy model of a machining centre in Figure 7, all the paths between any two nodes in the fault propagation digraph can be obtained and the paths are listed in Table 7. In reference to Equation (14) and Table 7, the edge betweenness of the fault propagation hierarchy model is calculated and the results are presented in Table 8 . 
Table 7. Statistical results of any two node paths.

\begin{tabular}{cc}
\hline Any Two Nodes & Paths \\
\hline $\mathrm{D} \rightarrow \mathrm{F}$ & $\mathrm{D} \rightarrow \mathrm{NC} \rightarrow \mathrm{F}, \mathrm{D} \rightarrow \mathrm{B} \rightarrow \mathrm{F}, \mathrm{D} \rightarrow \mathrm{W} \rightarrow \mathrm{F}$, \\
$\mathrm{D} \rightarrow \mathrm{B}$ & $\mathrm{D} \rightarrow \mathrm{NC} \rightarrow \mathrm{B} \rightarrow \mathrm{F}, \mathrm{D} \rightarrow \mathrm{NC} \rightarrow \mathrm{B}$ \\
$\mathrm{NC} \rightarrow \mathrm{F}$ & $\mathrm{NC} \rightarrow \mathrm{F}, \mathrm{NC} \rightarrow \mathrm{B} \rightarrow \mathrm{F}$ \\
$\mathrm{D} \rightarrow \mathrm{T}$ & $\mathrm{D} \rightarrow \mathrm{NC} \rightarrow \mathrm{B} \rightarrow \mathrm{T}, \mathrm{D} \rightarrow \mathrm{B} \rightarrow \mathrm{T}$ \\
$\mathrm{Q} \rightarrow \mathrm{F}$ & $\mathrm{Q} \rightarrow \mathrm{T}, \mathrm{Q} \rightarrow \mathrm{F} \rightarrow \mathrm{T}$ \\
$\mathrm{Q} \rightarrow \mathrm{T}$ & $\mathrm{R} \rightarrow \mathrm{T}, \mathrm{R} \rightarrow \mathrm{B} \rightarrow \mathrm{T}$ \\
$\mathrm{R} \rightarrow \mathrm{T}$ & $\mathrm{R} \rightarrow \mathrm{F}, \mathrm{R} \rightarrow \mathrm{B} \rightarrow \mathrm{F}$ \\
$\mathrm{R} \rightarrow \mathrm{F}$ & $\mathrm{H} \rightarrow \mathrm{T}, \mathrm{H} \rightarrow \mathrm{B} \rightarrow \mathrm{T}$ \\
$\mathrm{H} \rightarrow \mathrm{T}$ & $\mathrm{D} \rightarrow \mathrm{W}$ \\
$\mathrm{D} \rightarrow \mathrm{W}$ & $\mathrm{Q} \rightarrow \mathrm{B}$ \\
$\mathrm{Q} \rightarrow \mathrm{B}$ & $\mathrm{D} \rightarrow \mathrm{NC}$ \\
$\mathrm{D} \rightarrow \mathrm{NC}$ & $\mathrm{H} \rightarrow \mathrm{B}$ \\
$\mathrm{H} \rightarrow \mathrm{B}$ & $\mathrm{NC} \rightarrow \mathrm{B}$ \\
$\mathrm{NC} \rightarrow \mathrm{B}$ & $\mathrm{NC} \rightarrow \mathrm{B} \rightarrow \mathrm{T}$ \\
$\mathrm{NC} \rightarrow \mathrm{T}$ & $\mathrm{H} \rightarrow \mathrm{B} \rightarrow \mathrm{F}$ \\
$\mathrm{H} \rightarrow \mathrm{F}$ & $\mathrm{R} \rightarrow \mathrm{B}$ \\
$\mathrm{R} \rightarrow \mathrm{B}$ & $\mathrm{B} \rightarrow \mathrm{T}$ \\
$\mathrm{B} \rightarrow \mathrm{T}$ & $\mathrm{W} \rightarrow \mathrm{T}$ \\
$\mathrm{W} \rightarrow \mathrm{T}$ & $\mathrm{K} \rightarrow \mathrm{F}$ \\
$\mathrm{K} \rightarrow \mathrm{F}$ & $\mathrm{B} \rightarrow \mathrm{F}$ \\
$\mathrm{B} \rightarrow \mathrm{F}$ &
\end{tabular}

Table 8. The edge betweenness of the fault propagation hierarchy model of a machining centre.

\begin{tabular}{cccc}
\hline Directed Edge & $\boldsymbol{L}\left(\boldsymbol{v}_{\boldsymbol{i}}, \boldsymbol{v}_{j}\right)$ & Directed Edge & $\boldsymbol{L}\left(\boldsymbol{v}_{\boldsymbol{i}}, \boldsymbol{v}_{j}\right)$ \\
\hline$E\left(v_{R}, v_{B}\right)$ & 1 & $E\left(v_{Q}, v_{B}\right)$ & 1.5 \\
$E\left(v_{D}, v_{B}\right)$ & 0.75 & $E\left(v_{B}, v_{T}\right)$ & 3.5 \\
$E\left(v_{N C}, v_{B}\right)$ & 2.75 & $E\left(v_{B}, v_{F}\right)$ & 3.5 \\
$E\left(v_{H}, v_{B}\right)$ & 1.5 & $E\left(v_{R}, v_{T}\right)$ & 0 \\
$E\left(v_{D}, v_{N C}\right)$ & 1.5 & $E\left(v_{R}, v_{F}\right)$ & 0 \\
$E\left(v_{D}, v_{W}\right)$ & 0.25 & $E\left(v_{H}, v_{T}\right)$ & 0 \\
$E\left(v_{W}, v_{F}\right)$ & 0.25 & $E\left(v_{K}, v_{F}\right)$ & 0 \\
$E\left(v_{N C}, v_{F}\right)$ & 0.25 & $E\left(v_{Q}, v_{T}\right)$ & 0 \\
\hline
\end{tabular}

Table 8 reveals that the edge betweenness of different directed edges differs. Therefore, the influence of the structural characteristics of the model on the fault propagation also must be considered. The larger the edge betweenness value is, the more important the edge is in the fault propagation of a whole machine and greater consideration is required when the probability of being selected as the fault propagation path increases.

Therefore, on the basis of Equation (15), Tables 6 and 8, the fault propagation intensity of each directed edge at $1500 \mathrm{~h}$ can be obtained as shown in Table 9.

Table 9. Fault propagation intensity of each directed edge of a machining centre fault propagation model at $1500 \mathrm{~h}$.

\begin{tabular}{cccc}
\hline Directed Edge & $\boldsymbol{I n}\left(\boldsymbol{v}_{\boldsymbol{i}}, \boldsymbol{v}_{j}\right)$ & Directed Edge & $\boldsymbol{I n}\left(\boldsymbol{v}_{\boldsymbol{i}}, \boldsymbol{v}_{j}\right)$ \\
\hline$E\left(v_{R}, v_{B}\right)$ & 0.1396 & $E\left(v_{Q}, v_{B}\right)$ & 0.0775 \\
$E\left(v_{D}, v_{B}\right)$ & 0.1400 & $E\left(v_{B}, v_{T}\right)$ & 0.0314 \\
$E\left(v_{N C}, v_{B}\right)$ & 0.1231 & $E\left(v_{B}, v_{F}\right)$ & 0.0581 \\
$E\left(v_{H}, v_{B}\right)$ & 0.0740 & $E\left(v_{R}, v_{T}\right)$ & 0.0262 \\
$E\left(v_{D}, v_{N C}\right)$ & 0.0521 & $E\left(v_{R}, v_{F}\right)$ & 0.0267 \\
$E\left(v_{D}, v_{W}\right)$ & 0.0486 & $E\left(v_{H}, v_{T}\right)$ & 0.0368 \\
$E\left(v_{W}, v_{F}\right)$ & 0.0686 & $E\left(v_{K}, v_{F}\right)$ & 0.0477 \\
$E\left(v_{N C}, v_{F}\right)$ & 0.0212 & $E\left(v_{Q}, v_{T}\right)$ & 0.0283 \\
\hline
\end{tabular}


In reference to Figure 11 and Table 9, a hierarchy structure model of the fault propagation intensity of a machining centre can be obtained as shown in Figure 12.

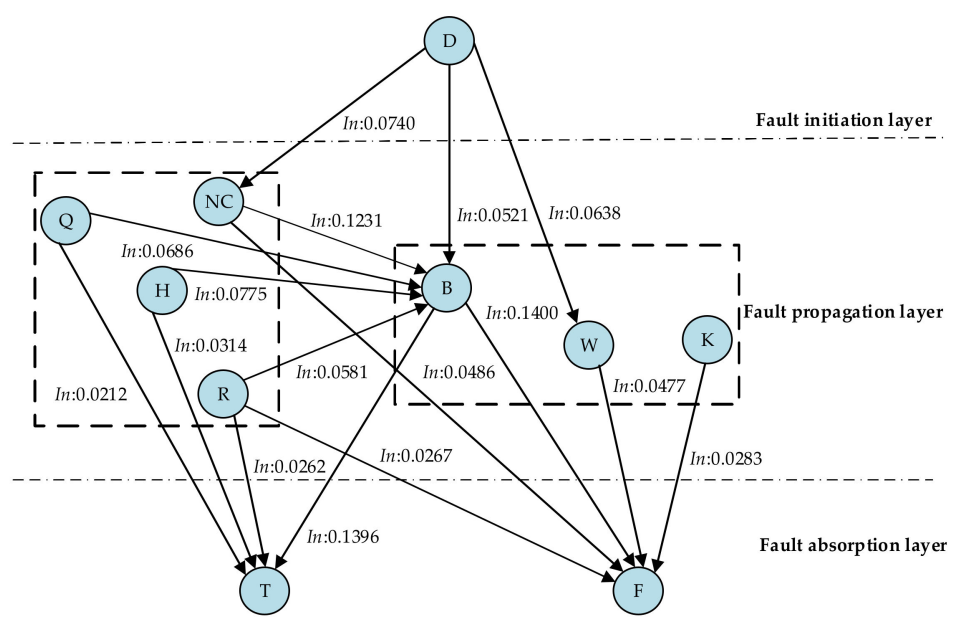

Figure 12. Hierarchy structure model of fault propagation intensity in a machining centre.

In reference to Equation (16) and Figure 11, the fault propagation probability values of each path in the fault propagation hierarchy model of a machining centre at $1500 \mathrm{~h}$ can be calculated as shown in Table 10.

Table 10. The fault propagation probability value of each path in the fault propagation model of a machining centre at $1500 \mathrm{~h}$.

\begin{tabular}{cr}
\hline Paths & $\boldsymbol{P}_{E}\left(\boldsymbol{v}_{i}, v_{j}\right)$ \\
\hline $\mathrm{D} \rightarrow \mathrm{NC} \rightarrow \mathrm{F}$ & 0.004799 \\
$\mathrm{D} \rightarrow \mathrm{NC} \rightarrow \mathrm{B} \rightarrow \mathrm{F}$ & 0.000342 \\
$\mathrm{D} \rightarrow \mathrm{NC} \rightarrow \mathrm{B} \rightarrow \mathrm{T}$ & 0.000338 \\
$\mathrm{D} \rightarrow \mathrm{B} \rightarrow \mathrm{F}$ & 0.004219 \\
$\mathrm{D} \rightarrow \mathrm{B} \rightarrow \mathrm{T}$ & 0.004178 \\
$\mathrm{D} \rightarrow \mathrm{W} \rightarrow \mathrm{F}$ & 0.004714 \\
$\mathrm{Q} \rightarrow \mathrm{T}$ & 0.042622 \\
$\mathrm{Q} \rightarrow \mathrm{B} \rightarrow \mathrm{F}$ & 0.003326 \\
$\mathrm{Q} \rightarrow \mathrm{B} \rightarrow \mathrm{T}$ & 0.003293 \\
$\mathrm{H} \rightarrow \mathrm{T}$ & 0.063015 \\
$\mathrm{H} \rightarrow \mathrm{B} \rightarrow \mathrm{T}$ & 0.004647 \\
$\mathrm{H} \rightarrow \mathrm{B} \rightarrow \mathrm{F}$ & 0.004692 \\
$\mathrm{R} \rightarrow \mathrm{T}$ & 0.052492 \\
$\mathrm{R} \rightarrow \mathrm{F}$ & 0.053345 \\
$\mathrm{R} \rightarrow \mathrm{B} \rightarrow \mathrm{T}$ & 0.003963 \\
$\mathrm{R} \rightarrow \mathrm{B} \rightarrow \mathrm{F}$ & 0.004001 \\
$\mathrm{~K} \rightarrow \mathrm{F}$ & 0.056592 \\
\hline
\end{tabular}

As expressed in Table 10, the fault propagation probability of each path is greater than the threshold value of $10^{-8}$; thus, a fault propagation phenomenon exists in the model.

Based on Table 9 and the hierarchy structure model of fault propagation in a machining centre, for the fault initiation layer there is only the electrical system component $D$. Hence, the critical node of the fault initiation layer is $D$. For the fault propagation layer at $1500 \mathrm{~h}$, $\operatorname{In}\left(v_{D}, v_{N C}\right)=0.0740>\operatorname{In}\left(v_{D}, v_{B}\right)=0.0521>\operatorname{In}\left(v_{D}, v_{W}\right)=0.0368$, thus the critical node currently is $N C$. This indicates that the fault is more likely to be transferred from the electrical system to the numerical control system. Given that $\operatorname{In}\left(v_{N C}, v_{B}\right)=0.1400>$ $\operatorname{In}\left(v_{N C}, v_{F}\right)=0.1396$, the critical node is $B$. Similarly, for the fault absorption layer system component node, $\operatorname{In}\left(v_{B}, v_{F}\right)>\operatorname{In}\left(v_{B}, v_{T}\right)$, thus the feed system $F$ is the critical component of this layer. Therefore at $1500 \mathrm{~h}$, the critical nodes are D, NC, B, and F, and the path 
composed of critical nodes is the critical fault propagation path. At $1500 \mathrm{~h}$, the most likely propagation path of the fault is $\mathrm{D} \rightarrow \mathrm{NC} \rightarrow \mathrm{B} \rightarrow \mathrm{F}$.

Similarly, the fault propagation intensity value of each directed edge of a machining centre at any time can be determined; in turn, the critical fault nodes and paths of a machining centre at any time can be obtained. This paper arbitrarily chooses the running time of $200 \mathrm{~h}$ and $5000 \mathrm{~h}$ as examples and draws the comparison diagram of the fault propagation intensity value of each directed edge as shown in Figure 13.

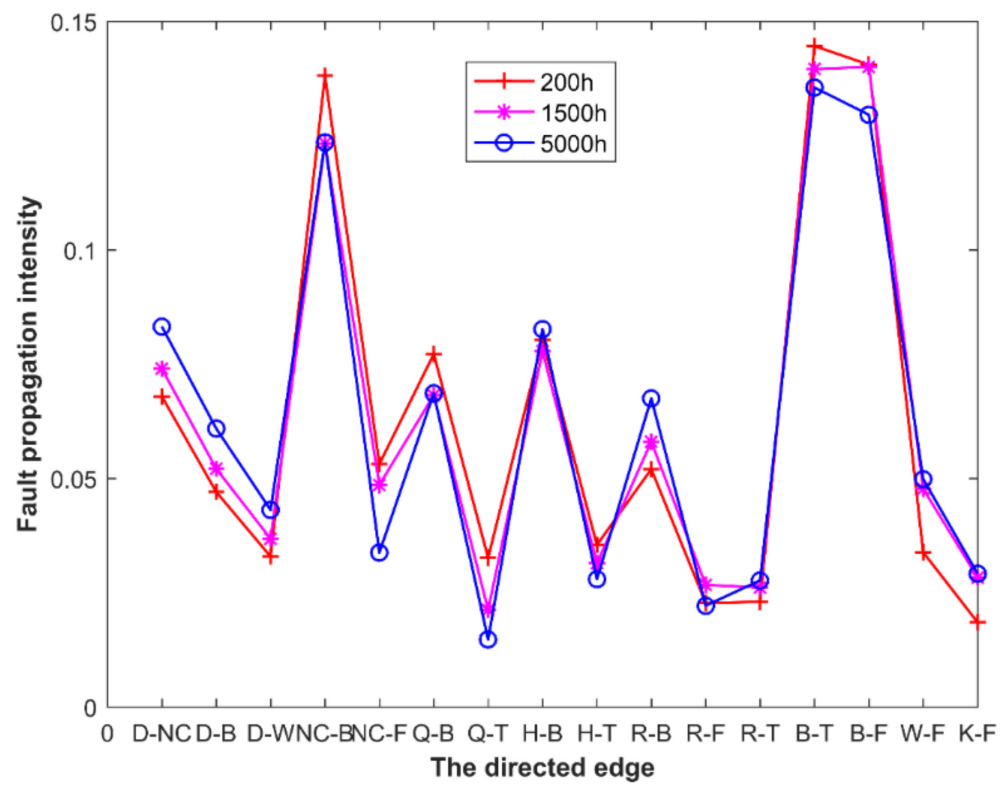

Figure 13. Comparison diagram of the fault propagation intensity of each directed edge at different times.

In reference to Figure 13, the fault propagation intensity values of each directed edge are varied at different times and the critical fault propagation paths of the machining centre at different times are distinct. The critical fault propagation path of $200 \mathrm{~h}$ is $\mathrm{D} \rightarrow \mathrm{NC} \rightarrow \mathrm{B} \rightarrow \mathrm{T}$, at $1500 \mathrm{~h}$ the critical fault propagation path is $\mathrm{D} \rightarrow \mathrm{NC} \rightarrow \mathrm{B} \rightarrow \mathrm{F}$, and at $5000 \mathrm{~h}$ the critical fault propagation path is $\mathrm{D} \rightarrow \mathrm{NC} \rightarrow \mathrm{B} \rightarrow \mathrm{T}$.

\subsection{Comparison Analysis}

The proposed method in this paper is compared with the importance evaluation method proposed in Reference [49]. When evaluating the importance of machine tool system components, the method in Reference [49] only evaluated the importance of components from the perspective of the fault propagation mechanism and did not consider the structural characteristics of the model. Combining the application examples in this paper, when the model structure characteristics are not considered and only the fault propagation mechanism is considered, the fault propagation probability value of each directed edge at $1500 \mathrm{~h}$ can be calculated according to Equations (10)-(13). Combined with the fault propagation hierarchy structure model of the machining centre in Figure 6, the fault propagation hierarchy structure model of the machining centre based on the fault propagation probability is drawn as shown in Figure 14. The model only considered the fault propagation mechanism of the machining centre. 


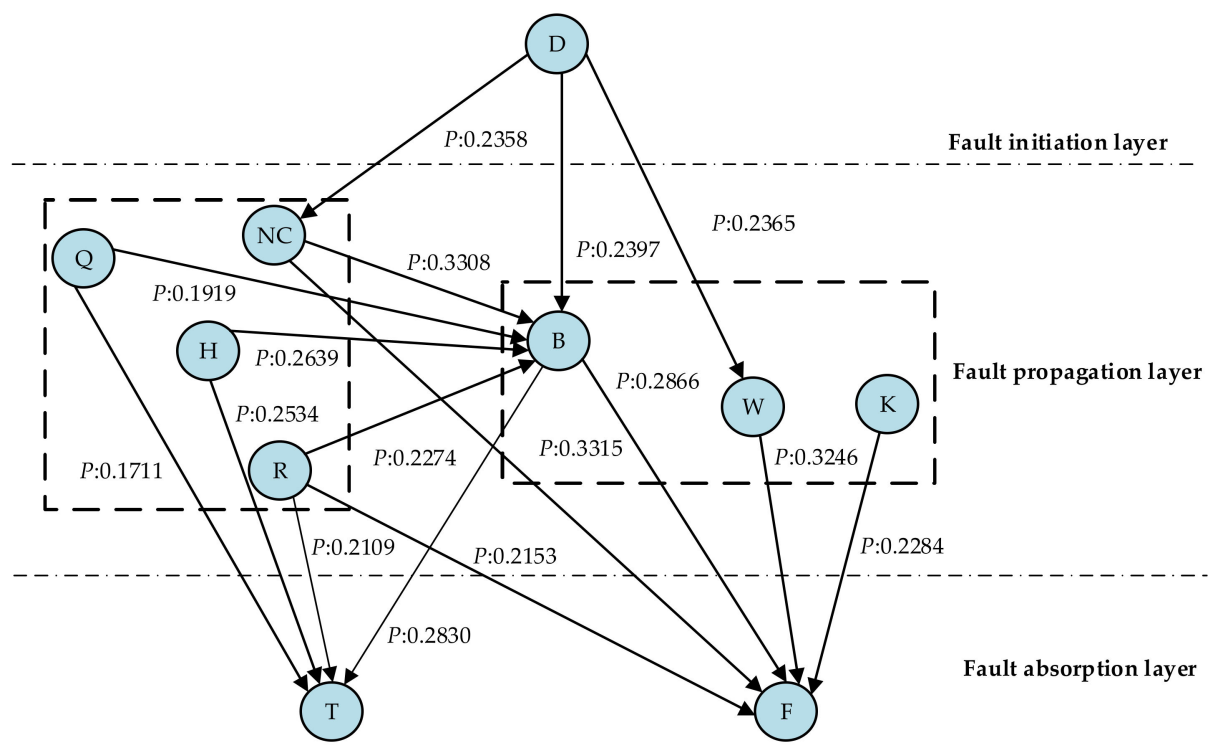

Figure 14. Hierarchy structure model of the machining centre based on the fault propagation probability.

As expressed in Figure 14 at $1500 \mathrm{~h}$, the fault source of the machining centre is component $\mathrm{D}$. The fault will propagate along the components with a high probability of fault propagation. As $P\left(v_{D}, v_{B}\right)=0.2397>P\left(v_{D}, v_{W}\right)=0.2365>P\left(v_{D}, v_{N C}\right)=0.2358$, the fault will preferentially propagate along $\mathrm{D} \rightarrow \mathrm{B}$ and because $P\left(v_{B}, v_{F}\right)=0.2866>$ $P\left(v_{B}, v_{T}\right)=0.2830$, the fault is more likely to propagate along $\mathrm{B} \rightarrow \mathrm{F}$. The critical fault propagation path at this time is $\mathrm{D} \rightarrow \mathrm{B} \rightarrow \mathrm{F}$ and the critical nodes are $\mathrm{D}, \mathrm{B}$, and $\mathrm{F}$. That is, at $1500 \mathrm{~h}$, the fault is most likely to be transmitted as such: electrical system $\rightarrow$ spindle system $\rightarrow$ feeding system. However, according to the method proposed in this paper, the result of calculation and analysis is $\mathrm{D} \rightarrow \mathrm{NC} \rightarrow \mathrm{B} \rightarrow \mathrm{F}$. There is a certain difference in the critical fault propagation path obtained by the two methods that is mainly because the method based on the fault propagation probability does not consider the structural characteristics of the model. The component NC plays an important role in the fault propagation structure model; when it fails, it will have a greater impact on the entire system, thus requiring attention. The influence of the structural characteristics of the model on the propagation of faults cannot be ignored. Therefore, the method proposed in this paper is more conducive to the analysis of the fault propagation behaviour of a machining centre and the analysis result is more reasonable.

\section{Discussion}

In reference to Tables 6 and 8 , the edge betweenness of the edge with a high probability of fault propagation is not necessarily large. For example, the fault propagation probability of the directed edge $E\left(v_{N C}, v_{B}\right)$ is the largest but its edge betweenness is not the largest. The edges with the largest betweenness are $E\left(v_{B}, v_{T}\right)$ and $E\left(v_{B}, v_{F}\right)$. Through comparative analysis of these examples, we can determine there is likely to be a certain deviation in the analysis of the fault propagation behaviour of a machining centre based on a single index. Therefore, the fault propagation mechanism and the structural characteristics of the model should be integrated to identify the critical fault nodes and critical fault propagation paths.

This paper takes the machining centre running for $1500 \mathrm{~h}$ as an example to explain the proposed method. We determine that the critical fault propagation path of a machining centre at $1500 \mathrm{~h}$ is $\mathrm{D} \rightarrow \mathrm{NC} \rightarrow \mathrm{B} \rightarrow \mathrm{F}$. Therefore, for a machining centre of the same model, when the running time is $1500 \mathrm{~h}$, the electrical system (D), numerical control system (NC), spindle system (B), and feed system (F) must be considered. These system components are more likely to fail and measures can be taken in advance to avoid faults.

Figure 13 illustrates that the critical system components and critical fault propagation paths are different at different stages of a machining centre's operation. Therefore, accord- 
ing to the fault propagation and evolution law of each system component of a machining centre, staff can make corresponding adjustments to the degree of attention necessary for the components of a machining centre during different stages of operation and can formulate appropriate fault prevention strategies.

\title{
6. Conclusions
}

This paper presents a dynamic analysis method of fault propagation behaviour of machining centres that can identify the critical fault propagation paths and nodes of a machining centre at any time. On this basis, fault warning and preventive maintenance can be conducted in a targeted manner, thereby reducing the economic loss and safety hazards of manufacturing enterprises due to equipment fault.

The method proposed in this paper mainly embodies the following advantages:

(1) The DSM-based fault propagation hierarchy structure model of a machining centre established in this paper can more clearly demonstrate the relationship between the system components in the form of a design structure matrix.

(2) There are certain differences in the influence degree of the edge between the components at the same level and the different levels. By introducing the Copula and the Coupling degree functions, the fault influence degree of edges between the same level and different levels are calculated, respectively. In this way, it is possible to more accurately measure the impact of faults between components.

(3) Considering the structural characteristics of the model and the fault mechanism of the system, a fault propagation intensity model of a machining centre is constructed and a quantitative description of the severity of fault propagation on the components is realized. According to the fault propagation intensity of the components, the critical fault propagation paths and nodes of a machining centre can be identified, can provide a reference for the fault maintenance, and encourage reliability growth of machining centres.

This paper demonstrates the effectiveness and practicability of the proposed method through the application of the specific case. In the future, the proposed fault propagation behaviour analysis method can be extended to other complex electromechanical products through sensor technology, rather than remaining at the level of theoretical guidance.

\begin{abstract}
Author Contributions: Conceptualization, L.M. and Y.Z.; methodology, L.M.; software, J.L.; validation, L.M. and Y.Z.; formal analysis, J.L.; investigation, L.M. and J.S.; resources, Y.Z.; data curation, Y.Z.; writing—original draft preparation, L.M.; writing—review and editing, L.M.; visualization, Y.Z. and F.Z.; supervision, J.L.; project administration, Y.Z.; funding acquisition, Y.Z. and L.M. All authors have read and agreed to the published version of the manuscript.

Funding: This research was funded by the Jilin Province Science and Technology Development Plan Project (Grant No. 20190302104GX), the Jilin Provincial Natural Science Foundation (Grant No. 20170101212JC), and the project 101832020DJX037 was supported by the Ph.D. Graduate Interdisciplinary Research of Jilin University.
\end{abstract}

Institutional Review Board Statement: Not applicable.

Informed Consent Statement: Not applicable.

Data Availability Statement: Not applicable.

Conflicts of Interest: The authors declare no conflict of interest.

\section{References}

1. Li, X.F. Research on the status QUO and development trend of numerical control technology. In Proceedings of the 2018 International Conference on Computational Science and Engineering (ICCSE 2018), Qingdao, China, 3-4 November 2018.

2. Martinova, L.I.; Martinov, G.M. Prospects for CNC machine tools. Russ. Eng. Res. 2019, 39, 1080-1083. [CrossRef]

3. Xing, L.D.; Zhao, G.L.; Wang, Y.J.; Xiang, Y.S. Reliability modelling of correlated competitions and dependent components with random failure propagation time. Qual. Reliab. Eng. Int. 2020, 36, 947-964. [CrossRef] 
4. Peukert, B.W.; Archenti, A. Dynamic interaction between precision machine tools and their foundations. Int. J. Autom. Technol. 2020, 14, 386-398. [CrossRef]

5. Gao, J.Z.; Yin, Y.F.; Fiondella, L.; Liu, L.J. Recovery of coupled networks after cascading failures. J. Syst. Eng. Electron. 2018, 29, 650-657.

6. Zhang, Y.Z.; Mu, L.M.; Shen, G.X.; Yu, Y.; Han, C.Y. Fault diagnosis strategy of CNC machine tools based on cascading failure. J. Intell. Manuf. 2019, 30, 2193-2202. [CrossRef]

7. Sheng, B.; Deng, C.; Xiong, Y.; Luo, Z.J.; Wang, Y.H. Fault diagnosis for CNC machine tool based on mapping model. Appl. Mech. Mater. 2014, 607, 739-742. [CrossRef]

8. Gao, Z.W.; Cecati, C.; Ding, S.X. A survey of fault diagnosis and fault-tolerant techniques-part I: Fault diagnosis with model-based and signal-based approaches. IEEE Trans. Ind. Electron. 2015, 62, 3757-3767. [CrossRef]

9. Gao, Z.W.; Cecati, C.; Ding, S.X. A survey of fault diagnosis and fault-tolerant techniques-part II: Fault diagnosis with knowledge-based and hybrid/active approaches. IEEE Trans. Ind. Electron. 2015, 62, 3768-3774. [CrossRef]

10. Feng, J.; Yao, Y.; Lu, S.; Liu, Y. Domain knowledge-based deep-broad learning framework for fault diagnosis. IEEE Trans. Ind. Electron. 2021, 68, 3454-3464. [CrossRef]

11. Kaluder, S.; Fekete, K.; Jozsa, L.; Klaic, Z. Fault diagnosis and identification in the distribution network using the fuzzy expert system. Eksploat. Niezawodn. Maint. Reliab. 2018, 20, 621-629. [CrossRef]

12. Zhou, Q.; Yan, P.; Liu, H.; Xin, Y.; Chen, Y. Research on a configurable method for fault diagnosis knowledge of machine tools and its application. Int. J. Adv. Manuf. Technol. 2018, 95, 937-960. [CrossRef]

13. Elimelech, O.; Stern, R.; Kalech, M. Structural abstraction for model-based diagnosis with a strong fault model. Knowl. Based Syst. 2018, 161, 357-374. [CrossRef]

14. Kouadri, A.; Hajji, M.; Harkat, M.-F.; Abodayeh, K.; Mansouri, M.; Nounou, H.; Nounou, M. Hidden markov model based principal component analysis for intelligent fault diagnosis of wind energy converter systems. Renew. Energy 2020, 150, 598-606. [CrossRef]

15. Song, W.L.; Xiang, J.W.; Zhong, Y.T. A simulation model based fault diagnosis method for bearings. J. Intell. Fuzzy Syst. 2018, 34, 3857-3867. [CrossRef]

16. Karabacak, Y.E.; Ozmen, N.G.; Gumusel, L. Worm gear condition monitoring and fault detection from thermal images via deep learning method. Eksploat. Niezawodn. Maint. Reliab. 2020, 22, 544-556.

17. Liang, L.; Wen, H.B.; Liu, F.; Li, G.; Li, M.L. Feature extraction of impulse faults for vibration signals based on sparse non-negative tensor factorization. Appl. Sci. 2019, 9, 3642. [CrossRef]

18. Nayana, B.R.; Geethanjali, P. Analysis of statistical time-domain features effectiveness in identification of bearing faults from vibration signal. IEEE Sens. J. 2017, 17, 5618-5625. [CrossRef]

19. Jung, D.; Ng, K.Y.; Frisk, E.; Krysander, M. Combining model-based diagnosis and data-driven anomaly classifiers for fault isolation. Control. Eng. Pract. 2018, 80, 146-156. [CrossRef]

20. Slimani, A.; Ribot, P.; Chanthery, E.; Rachedi, N. Fusion of model-based and data-based fault diagnosis approaches. IFACPapersOnLine 2018, 51, 1205-1211. [CrossRef]

21. Tabaszewski, M.; Szymanski, G.M. Engine valve clearance diagnostics based on vibration signals and machine learning methods. Eksploat. Niezawodn. Maint. Reliab. 2020, 22, 331-339. [CrossRef]

22. Zuber, N.; Bajric, R. Gearbox faults feature selection and severity classification using machine learning. Eksploat. Niezawodn. Maint. Reliab. 2020, 22, 748-756. [CrossRef]

23. Wu, Z.; Zhang, Q.; Cheng, L.F.; Tan, S.Y. A new method of two-stage planetary gearbox fault detection based on multi-sensor information fusion. Appl. Sci. 2019, 9, 5443. [CrossRef]

24. Gangsar, P.; Tiwari, R. Signal based condition monitoring techniques for fault detection and diagnosis of induction motors: A state-of-the-art review. Mech. Syst. Signal. Process. 2020, 144, 106908. [CrossRef]

25. Cho, K.-H.; Jo, H.-C.; Kim, E.-S.; Park, H.-A.; Park, J.H. Failure diagnosis method of photovoltaic generator using support vector machine. J. Electr. Eng. Technol. 2020, 15, 1669-1680. [CrossRef]

26. Goyal, D.; Choudhary, A.; Pabla, B.S.; Dhami, S.S. Support vector machines based non-contact fault diagnosis system for bearings. J. Intell. Manuf. 2020, 31, 1275-1289. [CrossRef]

27. Piltan, F.; Prosvirin, A.E.; Sohaib, M.; Saldivar, B.; Kim, J.M. An SVM-based neural adaptive variable structure observer for fault diagnosis and fault-tolerant control of a robot manipulator. Appl. Sci. 2020, 10, 1344. [CrossRef]

28. Gunerkar, R.S.; Jalan, A.K.; Belgamwar, S.U. Fault diagnosis of rolling element bearing based on artificial neural network. J. Mech. Sci. Technol. 2019, 33, 505-511. [CrossRef]

29. Marmouch, S.; Aroui, T.; Koubaa, Y. Statistical neural networks for induction machine fault diagnosis and features processing based on principal component analysis. IEEJ Trans. Electr. Electron. Eng. 2021, 16, 307-314. [CrossRef]

30. Wang, B.; Ke, H.W.; Ma, X.D.; Yu, B. Fault diagnosis method for engine control system based on probabilistic neural network and support vector machine. Appl. Sci. 2019, 9, 4122. [CrossRef]

31. Ruijters, E.; Stoelinga, M. Fault tree analysis: A survey of the state-of-the-art in modelling, analysis and tools. Comput. Sci. Rev. 2015, 15-16, 29-62. [CrossRef]

32. Chen, X. Research on fault early warning and the diagnosis of machine tools based on energy fault tree analysis. Proc. Inst. Mech. Eng. Part B J. Eng. Manuf. 2019, 233, 2147-2159. [CrossRef] 
33. Adler, C.O.; Dagli, C.H. A study of the effect of basic network characteristics on system-of-system failure propagation. Procedia Comput. Sci. 2014, 36, 345-352. [CrossRef]

34. Jin, L.; Wang, X.J.; Zhang, Y.; You, J.W. Cascading failure in multilayer networks with dynamic dependency groups. Chin. Phys. B 2018, 27, 737-744. [CrossRef]

35. Maza, S. Diagnosis modelling for dependability assessment of fault-tolerant systems based on stochastic activity networks. Qual Reliab. Eng. Int. 2015, 31, 963-976. [CrossRef]

36. Zakari, A.; Lee, S.P.; Chong, C.Y. Simultaneous localization of software faults based on complex network theory. IEEE Access 2018, 6, 23990-24002. [CrossRef]

37. Browning, T.R. Design structure matrix extensions and innovations: A survey and new opportunities. IEEE Trans. Eng. Manag. 2016, 63, 27-52. [CrossRef]

38. Son, H.; Kwon, Y.; Park, S.C.; Lee, S. Using a design structure matrix to support technology roadmapping for product-service systems. Technol. Anal. Strateg. Manag. 2018, 30,337-350. [CrossRef]

39. Li, Y.F.; Zhang, Y.J.; Dai, B.C.; Zhang, L. Dynamic importance analysis of components with known failure contribution of complex systems. Math. Probl. Eng. 2018, 2018, 8534065. [CrossRef]

40. Miziuła, P.; Navarro, J. Birnbaum importance measure for reliability systems with dependent components. IEEE Trans. Reliab. 2019, 68, 439-450. [CrossRef]

41. Peng, H.; Coit, D.W.; Feng, Q.M. Component reliability criticality or importance measures for systems with degrading components. IEEE Trans. Reliab. 2012, 61, 4-12. [CrossRef]

42. Hosseini Nodeh, Z.; Babapour Azar, A.; Khanjani Shiraz, R.; Khodayifar, S.; Pardalos, P.M. Joint chance constrained shortest path problem with Copula theory. J. Comb. Optim. 2020, 40, 110-140. [CrossRef]

43. Montes, I.; Miranda, E.; Palessoni, R.; Vicig, P. Sklar's theorem in an imprecise setting. Fuzzy Sets Syst. 2015, 278, 48-66. [CrossRef]

44. Peng, W.; Zhang, X.L.; Huang, H.Z. A failure rate interaction model for two-component systems based on copula function. Proc. Inst. Mech. Eng. Part O J. Risk Reliab. 2016, 230, 278-284. [CrossRef]

45. Neshat, M.; Sepidnam, G.; Sargolzaei, M.; Toosi, A.N. Artificial fish swarm algorithm: A survey of the state-of-the-art, hybridization, combinatorial and indicative applications. Artif. Intell. Rev. 2014, 42, 965-997. [CrossRef]

46. Fang, C.L.; Liu, H.M.; Li, G.D. International progress and evaluation on interactive coupling effects between urbanization and the eco-environment. J. Geogr. Sci. 2016, 26, 1081-1116. [CrossRef]

47. Shahrivari Joghan, H.; Bagheri, A.; Azad, M. Weighted label propagation based on local edge betweenness. J. Supercomput. 2019, 75, 8094-8114. [CrossRef]

48. Guo, L. Research on Failure Propagation Mechanism for Machine Integration System. Master's Thesis, Beijing Jiaotong University, Beijing, China, 2015.

49. Zhang, Y.Z.; Liang, S.B.; Liu, J.L.; Cao, P.L.; Luan, L. Evaluation for machine tool components importance based on improved leaderRank. Proc. Inst. Mech. Eng. Part O J. Risk Reliab. 2021, 235, 331-337. 